\title{
Caracterización de los crímenes de estado y el proceso de paz en Colombia*
}

\author{
Characterization of State Crimes and the peace process in Colombia. \\ Caracterização dos Crimes do Estado e do processo de paz na Colômbia.
}

DOI: https://doi.org/10.21803/pensam.v11121-1.268

John José Libreros Díaz

https://orcid.org/0000-0002-4418-3967

\section{¿Cómo citar este artículo?}

Libreros, J. (2018). Caracterización de los crímenes de estado y el proceso de paz en Colombia. Pensamiento Americano, 11(22), 100-120. DOI: https://doi.org/10.21803/pensam.v17i21-1.268

\begin{abstract}
Resumen
Este artículo académico destacará que la búsqueda de la paz ha sido un anhelo universal en todos los tiempos. Lo evidencian los numerosos procesos de justicia transicional acaecidos en diferentes países del mundo, y Colombia no es la excepción.

En Colombia se han dado muchos intentos por alcanzar una paz estable y duradera. El más reciente culminó con la firma del Acuerdo de Paz de La Habana, entre el Estado colombiano y la extinta guerrilla de las FARC. Se resaltará que en el marco del conflicto, se produjeron excesos por parte de sus actores, especialmente, por algunos miembros de la Fuerza Pública, los que en aras de mostrar resultados en su lucha contra la subversión, cometieron homicidios aleves contra civiles inermes, ajenos al conflicto armado. Todo bajo la égida perversa del sistema de incentivos y recompensas emanado del Poder Ejecutivo e implementado mediante directrices del Ministerio de Defensa que desembocó en crímenes de Estado y de lesa humanidad, comúnmente conocidos como "Falsos Positivos" y en la eventual vinculación de sus perpetradores a la Justicia Especial para la Paz.
\end{abstract}

Palabras Claves: proceso de paz, justicia transicional, "falsos positivos" y Crímenes de Estado.

\begin{abstract}
This paper will highlight that the search for peace has been a universal yearning for all time. It is evidenced by the numerous transitional justice processes that have occurred in different countries of the world, and Colombia is no exception.

Many attempts have been made in Colombia to achieve a stable and lasting peace. The most recent culminated in the signing of the Havana Peace Agreement, between the Colombian State and the extinct FARC guerrillas. It will be noted that in the context of such a conflict, there were excesses by its actors, especially by some members of the Public Force, who, in order to show results in their fight against subversion, committed homicides against civilians, foreign, alien to the armed conflict. All under the perverse aegis of the system of incentives and rewards emanated from the Executive Power and implemented through guidelines of the Ministry of Defense that led to crimes of State and against humanity, commonly known as "False Positives" and the eventual linking of their perpetrators to the Special Justice for Peace.
\end{abstract}

Keywords: peace process, transitional justice, "false positives" and State Crimes

\footnotetext{
* El artículo hace parte de la investigación adelantada por el autor denominada "Los Crímenes de Estado y el Proceso de Paz en Colombia" en virtud de la formación en el Programa de Doctorado en Ciencias Sociales y Jurídicas de la Escuela Internacional de Doctorado de la Universidad Rey Juan Carlos de Madrid, España.
} 


\section{Resumo}

Este artigo académico destaca que a busca da paz tem sido um objetivo universal em todos os tempos. Como evidência temos os numerosos processos de justiça transicional nos diferentes países do mundo, e a Colômbia não é a exceção.

Na Colômbia se realizou várias tentativas para alcançar uma paz estável e duradoura. A mais recente culminou com a assinatura do Acordo de Paz de Havana, entre o Estado Colombiano e a extinta guerrilha das FARC. Será ressaltado que no marco do conflito se produziram excessos por parte de seus atores, especialmente por alguns membros da Força Pública, os que com as ganas de mostrar resultados em sua luta contra a subversão cometeram homicídios contra civis alheios ao conflito armado. Tudo isso sob a prática do sistema de incentivos e recompensas do poder Executivo e implementado mediante diretrizes do Ministério da Defesa que resultou em crimes de Estado e de lesa humanidade, comumente conhecidos como "falsos positivos", e na eventual vinculação de seus perpetradores à Justiça Especial para a Paz.

Keywords: processo de paz, justiça transicional, "falsos positivos" e Crimes Estatais.

\section{Perfil}

Master di Secondo Livello in Argomentazione Giuridica Università Degli Studi di Palermo 2014-2015. Máster en Argumentación Jurídica Universidad de Alicante. 2014-2015. Universidad Rey Juan Carlos de Madrid (España). toto421@hotmail.com.

John José Libreros Díaz

Doctorando en Ciencias Sociales y Jurídicas. 


\section{Consideraciones previas respecto a la ca- racterización de los Crímenes de Estado}

ntes de entrar a dilucidar los criterios
o exigencias que caracterizan los Crí-
menes de Estado, es necesario hacer algunas precisiones relacionadas con el manejo del lenguaje que en algunas ocasiones se convierte en el punto de partida de falsas oposiciones cuando se trata de conceptualizar o caracterizar figuras jurídicas de tanto impacto en el devenir histórico de la humanidad.

Se señala lo anterior porque los diversos criterios que se esbozan en un momento dado para tratar de arribar a una aproximación de dicho concepto no se oponen o contradicen, sino que por el contrario suman para determinar qué se entiende o se ha entendido como Crímenes de Estado sobre todo, cuando el manejo del lenguaje cotidiano es elevado al lenguaje del Derecho.

En este sentido, Gustavo Salas (2012), en el prólogo de la obra Delitos contra la Humanidad, expresa:

El Derecho es -lenguaje positivado- y si hay descuidos en su concepción y construcción, puede pervertirse en ser un mero símbolo para la dominación selectiva; un Derecho para imponer el dominio de los pocos sobre los muchos. Vemos en esta desviación, la manía indeseada de querer mirar al Derecho como una espada que lastima, cuando en verdad nació como un escudo que protege. Este lenguaje positivado llega a cobrar el papel de conciencia de lo real en las comunidades humanas, con criterios de verdad y tal no es siempre lo correcto, ni lo justo. Por eso mismo, es necesario desenmascarar muchos mitos que parecían verdades eternas -los dogmas-... (p.2).

Por otra parte, el lenguaje puede convertir- se asimismo en una herramienta política que desvíe la atención hacia otros asuntos que no guardan estrecha relación con el mensaje que el interlocutor quiere enviar a sus destinatarios, con los inconvenientes que esto puede acarrear al momento de interpretarlo, vale decir, incertidumbre, imprecisión o vaguedad.

Las dificultades prácticas pueden superarse si tomamos la precaución de precisar, en todos los casos de posible duda, el sentido con que hemos empleado tal o cual palabra o expresión...

Si se nos pide que hagamos explícito el criterio de aplicación de una palabra podemos indicar un cierto número de características, o propiedades definitorias, y creer que todas las otras propiedades posibles no incluidas entre aquellas están, por ello, excluidas como no relevantes. Esta creencia es equivocada. Sólo pueden reputarse excluidas como irrelevantes las propiedades o características posibles que han sido consideradas, pero no las que no lo han sido. Estas últimas no están excluidas; cuando se presenta un caso en el que aparece una o más de ellas es perfectamente legítimo que sintamos dudas que no pueden ser eliminadas por un proceso de pura deducción a partir del significado corriente de las palabras. El uso puede estar, a este respecto, totalmente "abierto". Es decir, no decidido o, en otros términos, dispuesto a admitir extensiones o restricciones (Carrió, 1990, p.34).

Antes de señalar las características de los delitos de lesa humanidad, íntimamente relacionados con las ejecuciones extrajudiciales denominadas "Falsos Positivos", se debe aclarar que se intentará esbozarlas sin pretensiones de exhaustividad. Por tanto, se resaltarán aspectos particularizantes de tales conductas punibles.

Pensamiento Americano Vol. 11 (22) • 2018 • Julio-Diciembre · Corporación Universitaria Americana · Barranquilla, Colombia • ISSN: $2027-2448$. 
Consisten en un ataque generalizado o sistemático en contra de una población civil, que se lleva a cabo en cumplimiento de una política. Un crimen de lesa humanidad puede consistir en una única atrocidad, como una masacre o en múltiples crímenes. Además, siguen un patrón o tiene un mismo modus operandi, es decir, las mismas víctimas, los mismos perpetradores, la misma política, los mismos objetivos. No se trata de casos aislados, se trata de casos sistemáticos.

Se caracteriza además, por constituir una forma de criminalidad no convencional y asimismo, forma parte de la llamada criminalidad color caqui que conllevan altos índices de impunidad.

...Criminalidad no convencional es la protegida por posiciones oficiales o semioficiales en contra de la ley y los usos internacionales, como los fraudes económicos y financieros, la alta corrupción, el comercio ilícito, la explotación del trabajo, la discriminación, el genocidio, la falsa publicidad y, en fin, todas aquellas acciones que aun recogidas por la ley penal quedan impunes; añádanse otras formas hoy frecuentes, como desapariciones, torturas, persecución política y racial, castigo cruel e inhumano, denegación de justicia, etc...

Por sus agentes se habla de criminalidad: ...Color caqui. Nombre que se da a los hechos causantes de daño social cometidos por los militares en tiempo de guerra... (Pérez Pinzón, 1986, p. 50).

Lo expresado, si se tiene en cuenta que, entratándose de las ejecuciones extrajudiciales o Crímenes de Estado y para el caso colombiano los "Falsos Positivos", solamente se ha logrado judicializar y penalizar a algunos miembros de bajo rango, pertenecientes al Ejercito Nacional, no habiéndose vinculado penalmente en muchos casos a los superiores jerárquicos relacionados con la doctrina de la responsabilidad de mando. Abriéndose eventualmente la posibilidad de la intervención de las Cortes Internacionales de Derechos Humanos ante la manifiesta impunidad.

A propósito de esto último, de acuerdo con la Revista Semana ("Las cuatro críticas", 2017), ya se produjeron pronunciamientos oficiales. Por ejemplo, la Carta de la Fiscal de la Corte Penal Internacional Fatou Bensouda donde a instancias de la Corte Constitucional, precisó entre otras cosas:

La fiscal de la CPI expresa que los jefes y otros mandos superiores son penalmente responsables de los crímenes cometidos por sus subordinados si sabían, o tenían razones para saber, que éstos iban a cometer o estaban cometiendo crímenes, y no tomaron todas las medidas razonables y necesarias a su alcance para evitar que se cometieran o, si ya se habían cometido, para castigar a los responsables (pág. 3).

En este sentido establece los aspectos a tener en cuenta para determinar esa responsabilidad de mando.

\section{- Capacidad legal y material de emitir ór- denes}

Asimismo, el documento cuestiona que el artículo transitorio 24 del Acto Legislativo exija, para determinar la responsabilidad de mando de un crimen, que el superior haya tenido la capacidad efectiva de desarrollar y ejecutar operaciones dentro del área de responsabilidad asignada a la unidad bajo el mando del jefe militar, según el rango correspondiente. Asegura que esta medida ignora la realidad de los poderes que el superior hubiere podido tener realmente. 
Al respecto se sigue señalando en la Revista Semana ("Las cuatro críticas", 2017) "para efectos de determinar la responsabilidad como jefe militar, ni el Derecho Internacional consuetudinario ni el Estatuto de Roma dan importancia jurídica alguna al concepto del "área de responsabilidad". Por el contrario, la cuestión jurídicamente importante es solamente si el superior tenía "control efectivo" (p.4), sobre los autores de los crímenes al momento en que fueron cometidos, en el sentido de la capacidad material de prevenir sus crímenes futuros o de castigar los crímenes pasados.

\section{Conceptualización}

Colombia durante muchísimos años ha vivido sumida en la violencia por la conjugación de diversos factores. Entre otros, por el surgimiento en el territorio nacional de grupos rebeldes, conocidos como guerrilleros, los que mediante el empleo de las armas pretendían derrocar al Gobierno Nacional o suprimir o modificar el régimen constitucional o legal vigente. Circunstancia que suscitó la respuesta del Estado, a través de sus Fuerzas Militares, con el fin de defender, restablecer y mantener su Soberanía, lo que desencadenó en un conflicto armado, permanente y de baja intensidad.

En este orden de ideas, se debe resaltar que el conflicto armado que vive Colombia desde hace más de medio siglo se agudizó por el surgimiento de nuevas, alarmantes, inconcebibles, intolerables y absolutamente repudiables prácticas realizadas por los Cuerpos de Seguridad del Estado. En consecuencia, es el momento de analizar tales comportamientos como Crímenes de Estado y su incidencia en el Proceso de Paz en Colombia.

Recuérdese que la Carta Política, en su artículo 22 señala:
"La paz es un derecho y un deber de obligatorio cumplimiento. (Const., 1991)" Pero la misma, no puede materializarse a cualquier precio. Por ejemplo, desconociendo los cánones reguladores de los Derechos Humanosy del Derecho Internacional Humanitario o sin tener en cuenta su propia memoria histórica como también la de algunos Estados que se han visto abocados a procesos de Justicia Transicional por haber padecido conflictos similares.

A partir de la caracterización de ciertas construcciones relacionadas con el tema, puede derivarse una buena teoría o por el contrario, puede pervertirse convirtiéndose en un inconveniente para un abordaje productivo, alejado de un dogmatismo sin razón. Por ello, es necesario acudir a la precisión lingüística y al manejo adecuado de las categorías del caso, para poder concretar su significado y su alcance filosófico y socio-jurídico e igualmente, precisar las particularidades de los denominados Crímenes de Estado.

Asimismo, se requiere en este acápite resaltar las experiencias arrojadas en los procesos de justicia transicional que se han suscitado en otros contextos, para ser aprovechadas en el proceso de paz de Colombia. En este orden de ideas, se desarrollarán los enfoques filosófico, sociológico y jurídico, dejando de lado otros a los que se ha aludido no porque estos no sean importantes, sino porque los precitados guardan una más estrecha relación con el eje temático del presente estudio.

\section{Enfoque filosófico}

El aspecto filosófico de los Crímenes de Estado es escasamente considerado por los muy diversos estudiosos del tema, quienes dirigen principalmente su atención a los matices jurídicos, políticos y sociales. Pero no obstante, es del caso aclarar que no se trata de filosofar por filosofar sobre los Crímenes

Pensamiento Americano Vol. 11 (22) • 2018 • Julio-Diciembre · Corporación Universitaria Americana · Barranquilla, Colombia • ISSN: $2027-2448$. 
de Estado sino de conceptualizar desde un ámbito más específico, desde la Filosofía Política y de la Filosofía del Derecho en aras de establecer su esencia o naturaleza, pero sin olvidar que tales comportamientos humanos han permanecido a través de la historia de la humanidad vinculados con el tejido social, con los regímenes de gobierno y con la ineficacia de la administración de justicia y en consecuencia, con la vulneración permanente de los derechos humanos.

Los Crímenes de Estado y la convivencia pacífica de los pueblos han sido apreciados por diversos filósofos, pero subrayándose que la mayoría de éstos lo han perfilado más desde la guerra que de la paz. Por ello, se quiere resaltar la figura del filósofo Immanuel Kant por sus lúcidas reflexiones sobre lo que para muchos es considerado un sueño sin cumplir, o sea, su desiderátum: la paz perpetua.

Por derecho propio KANT se ha ganado la fama de "filósofo de la paz", por excelencia, con su bello fascículo cuyo significado histórico no es tanto la idea de paz para solucionar conflictos bélicos, sino el proyecto de hacerla permanente, "perpetúa", vale decir, según BOBBIO "de hacer por primera vez posible un mundo en el que la guerra sea desechada para siempre como forma de resolver controversias entre los Estados...

...a partir de la Edad Antigua hasta llegar a la modernidad con BETHUME, Duque de Sully, BENTHAM, HOBBES, PENN, el abate Sant-PIERRE, ROUSSEAU, precisando que los autores privilegian la guerra frente a la paz, tradición que rompe KANT al abogar por una "paz perpetua" considerada como el fin supremo del "derecho de gentes", hoy conocido como derecho Internacional público, aportación valiosa a esta rama del derecho. En este sentido,
KANT ocupa un sitio de mucho honor en la historia del derecho internacional, desde el punto de vista jurídico, moral y político; máxime cuando dicha aportación se encuentra iluminada por el filosofar de un gran sabio, cuyo pensamiento en varios campos de la vida continúa vigente, lleno de frescura, tal como sucede con la tesis de la "Federación de Estados Libres", democráticos, soberanos, no intervencionistas, con un derecho cosmopolita, una ciudadanía universal, sin ejércitos permanentes, para buscar una paz duradera, tesis de (sic) que empezó a tomar cuerpo en la realidad mundial, desde la Sociedad de Naciones de 1919 y la Organización de Naciones Unidas de 1945, organizaciones que nacieron en un clima difícil, sin que hayan logrado detener las guerras nacionales o locales; pero, que si han logrado disipar hasta la fecha, una nueva conflagración mundial... (Ortíz Rivas, 2004, p.14).

De otro lado, y para dilucidar sobre la naturaleza de los Crímenes de Estado desde el ámbito ontológico se debe reflexionar en primer lugar sobre qué se entiende por esta rama de la filosofía y luego, desentrañar la esencia y la razón de ser de aquellos como también el propósito o fines de sus perpetradores.

En este orden de ideas, se ha expresado que el origen etimológico de Ontología proviene del griego ontos, ser + logos, tratado. Es considerada como una parte de la metafísica que estudia el ser en general y sus propiedades trascendentales. Aristóteles la llamó filosofía primera, y Andrónico de Rodas metafísica. Pero fue Cristian Wolff quien Ilamó Ontología al estudio sobre lo que es común a todo ser tanto real como posible, que debe anteponerse al de los seres existentes de hecho (mundo, alma, Dios) (Larousse Gran Diccionario, 2016, p.1). 
Por tanto, se tratará de explicar desde el mencionado punto de vista lo que se entiende como Crímenes de Estado, pero desde un ámbito más restringido, vale aclarar, desde la Filosofía del Derecho.

De esa manera, el teórico Alberto Montoro Ballesteros (2000) manifiesta:

Desde el plano propio de la Teoría fundamental del Derecho (ontología jurídica formal) un planteamiento unitario y sistemático del fenómeno de la infracción jurídica nos permite distinguir los siguientes tipos y especies de la misma:

a) Actos que violan el Derecho en cuanto sistema de legalidad y de legitimidad. Dentro de este género encontramos las siguientes especies: $1^{\circ}$.- El acto ilícito civil; $2^{\circ}$.- El acto ilícito penal (delito común); $3^{\circ}$.- El acto arbitrario (ilegal) e injusto.

b) Actos que violan el Derecho en cuanto sistema de legalidad pero no en cuanto sistema de legitimidad. Este tipo de acto contrario al Derecho comprende a su vez las siguientes especies: $1^{\circ}$.- El acto meramente ilegal; $2^{\circ}$.- El acto ilegal pero legitimo por razón de su materia o contenido. Aquí es donde encontraría su acomodo sistemático más riguroso el denominado (delito político); $3^{\circ}$.- El acto arbitrario (ilegal) y materialmente justo.

c) Actos que violan el Derecho en cuanto sistema de legitimidad pero no en cuanto sistema de legalidad. Se comprenden aquí determinados supuestos de criminalidad común que gozan de la cobertura legal del Estado. Tal es el supuesto de los denominados crímenes de Estado o terrorismo de Estado.

d) Actos que violan el Derecho en cuan- to sistema de legitimidad y de legalidad pero que poseen la apariencia formal de la legalidad. A este género pertenecen como especies del mismo: $1^{\circ}$. - El fraude de ley; $2^{\circ}$. - El abuso de Derecho; $3^{\circ}$. - La desviación de poder (p.138).

\section{Enfoque sociológico}

Para desarrollar el presente enfoque relacionado con las denominadas "Ejecuciones Extrajudiciales" comúnmente conocidas en Colombia como "Falsos Positivos", es preciso contextualizar el ámbito en que surgieron esta clase de prácticas vulneradoras de la dignidad de la humanidad en general y de la dignidad humana en particular. Por ello, se ubicará el momento histórico en que las mismas surgieron, las circunstancias socioeconómicas de las víctimas, la caracterización de los victimarios y desde luego, se vincularán con la lucha armada y contrainsurgente que se libraba en el país; e igualmente, de todas las medidas que se adoptaron por parte del Estado para tratar de derrotar a los grupos guerrilleros. No obstante, la importancia de este enfoque, por ahora se enfatizará que los crímenes atroces se producen a gran escala y no son actos espontáneos o aislados; son procesos, con historias, precursores y factores desencadenantes que, combinados, posibilitan su comisión.

\section{Enfoque jurídico.}

Los doctrinantes del Derecho Penal Internacional se refieren a los crímenes atroces en tres modalidades a saber: crímenes internacionales definidos jurídicamente: genocidio, crímenes de lesa humanidad y crímenes de guerra.

En cuanto a los crímenes de lesa humanidad de tiempo atrás se pueden reseñar diversas definiciones. Las que fueron plasmadas en 
diferentes Instrumentos inherentes al Derecho Penal Internacional.

Al efecto, pueden encontrarse en la Convención para la Prevención y la Sanción del Delito de Genocidio de 1948, los Convenios de Ginebra de 1949 y sus Protocolos Adicionales de 1977 y el Estatuto de Roma de la Corte Penal Internacional de 1998, entre otros tratados.

Por lo general los conflictos armados son el caldo de cultivo para que se produzca el incremento de las diversas formas de violencia (estructural, institucional o individual) y desde luego su aparejada impunidad aunada a la permisividad de comportamientos que en diferentes circunstancias no serían de recibo ni mucho menos susceptibles de aceptación social. Todo en contubernio con una especie muy particular de sensación cognitiva de inseguridad.

De todas maneras, es menester señalar que las mencionadas conductas se suscitan cuando los Estados viven altos niveles de inestabilidad política que amenazan su seguridad y además, colocan en alto riesgo su equilibrio en los asuntos económicos o sociales. Así las cosas, se puede afirmar, que si bien es cierto que las situaciones de conflicto armado necesariamente pueden conllevar a la comisión de Crímenes de Estado también lo es, que tales circunstancias los incrementan en alto grado de probabilidad.

En tal sentido, se intentará establecer las características de los delitos de lesa humanidad integradores de la categoría de crímenes atroces y desde luego, de su muy particular especie, las ejecuciones extrajudiciales, mal Ilamadas en Colombia: "Falsos Positivos".

Respecto al marco jurídico nacional, la Constitución colombiana autoriza el denominado Bloque de Constitucionalidad mediante el cual se incorporan al Derecho interno los
Tratados o Pactos Internacionales de Derechos Humanos y de Derecho Internacional Humanitario debidamente aprobados y ratificados por el Congreso de la República de Colombia, verbi gratia, el Estatuto de Roma, que entró a regir diez años después de su aprobación parlamentaria y sanción presidencial.

Por otro lado, vale la pena reiterar una aproximación del significado jurídico de los delitos de lesa humanidad y, por tanto, un acercamiento a los que se entiende por ejecuciones extrajudiciales, o sea, los llamados "Falsos Positivos:

Debido a su carácter ex novo y con motivo de la carencia de un tratado que los definiera de forma consensada, los crímenes contra la humanidad han sido definidos evolutivamente por diferentes instrumentos internacionales y por la actividad jurisdiccional de los tribunales penales internacionales creados a lo largo de la historia hasta llegar a la Corte Penal Internacional. De esta manera, el derecho penal internacional, tanto consuetudinario como positivo, ha representado un medio cooperativo jurídico competente para combatir este tipo de actos; primero, a través de desarrollar su paulatina conceptualización y final codificación y, segundo, por medio de permitir el juzgamiento y la sanción de los responsables de dichos crímenes. Por consiguiente, la evolución de la definición del crimen contra la humanidad representa una importante herramienta jurídica que ha ayudado a consolidar el derecho penal internacional (Servín Rodríguez, 2014, p. 214).

En este orden de ideas, debe destacarse que en el devenir histórico de los crímenes de lesa humanidad ha permanecido en un lugar común relacionado con el desconocimiento del 
estricto Principio de Legalidad. En el entendido que estos no se han plasmado de manera clara e inequívoca, desde el campo normativo. En consecuencia, esta falencia jugó en contra de la penalización de los mismos y solamente a partir del desarrollo doctrinal y jurisprudencial emanado de las Cortes Internacionales de Derechos Humanos comenzaron a adecuarse dichos comportamientos desde la óptica del Principio de Determinación o Tipicidad Inequívoca.

De tal forma, los crímenes de lesa humanidad no se han positivizado en una normativa específica, tal como sucede con el genocidio y los crímenes de guerra. Sin embargo, su definición ha sido producto del Derecho Consuetudinario y muy particularmente, el resultado de las interpretaciones y argumentaciones esgrimidas en los pronunciamientos emanados de los Tribunales Internacionales de Derecho Humanos.

\section{Precedentes internacionales}

Para efectos del presente estudio, se considera necesario traer a colación las experiencias fácticas y jurídicas suscitadas, con ocasión de la implementación de procesos de justicia transicional, como instrumento jurídico fundamentado en previos acuerdos de paz y su posterior fase de postconflicto.

De modo que se analizarán las diferentes circunstancias histórico-materiales acaecidas en disimiles contextos mundiales. Por tanto, se hará un recuento de algunos aspectos que los rodearon a saber: políticos, socio-culturales y jurídicos, entre otros, con el fin de aprovechar las experiencias más sobresalientes de otras latitudes y no repetir las mismas falencias o errores, es decir, discernir entre lo positivo y lo negativo y rescatar lo pertinente en aras de una salida efectiva y eficaz del sui generis proceso de paz que se vive en
Colombia de cara a los crímenes de Estado, peculiarmente llamados "Falsos Positivos".

En este orden de ideas, se relacionará de forma sucinta lo acontecido en algunos países que de alguna manera han vivido -en algún momento de su historia- algunas formas de justicia transicional, después de haber padecido períodos de violencia, de luchas intestinas o de conflictos internos que finalmente le apostaron a ciertas salidas concertadas o consensuadas que conllevaran a la paz duradera de sus coasociados.

\section{En Europa}

En cuanto al continente europeo se seleccionarán a Grecia, Alemania y España, por considerarse de mayor relevancia en cuanto tienen ciertos puntos convergentes con el caso colombiano.

Respecto a Grecia se precisa el denominado régimen sangriento de los "Treinta Tiranos" que cometió numerosas ejecuciones extrajudiciales, expropió a miles de personas y además, provocó el desplazamiento forzado de muchísimos habitantes de su territorio nacional.

El primer caso bien documentado sobre justicia transicional o de transición, data del año 404 A.C., y ocurrió en Atenas, Grecia, como resultado de un golpe de estado de una clase de la oligarquía, encabezado por los llamados "Treinta Tiranos". Este nuevo gobierno de facto condujo a la ejecución extrajudicial de casi el 10\% de los ciudadanos, la confiscación de bienes de miles de personas y la expulsión de más de la mitad de la población. No obstante, después de un período de ocho meses de guerra civil y de derrocar a los oligarcas tiranos, los atenienses decidieron aplicar una cuidadosa y original fórmula de justicia... 
...Los miembros del antiguo régimen de los "Treinta Tiranos" recibieron una amnistía bajo ciertas condiciones tales como ayudar al restablecimiento de la armonía social y la reconciliación, decir la verdad ante los tribunales, promover la unidad nacional y apoyar el establecimiento de una memoria colectiva sobre sus culpas y los daños causados... (Vélez Gutiérrez, 2015, p. 115).

En consideración a lo reseñado se estima de acuerdo con el citado jurista que del proceso transicional ateniense aprenderán los colombianos el perdón y la amnistía para algunos casos bajo el amparo de la verdad de lo ocurrido, de la autoincriminación de los responsables, la reconciliación entre víctimas y victimariosy la no repetición.

Ahora bien, en cuanto al caso alemán surgen las imágenes de los Juicios de Núremberg, estos consistieron en una serie de procesos jurisdiccionales adelantados contra líderes, Agentes del Estado y demás colabores del régimen nacionalsocialista de Adolf Hitler. Asunto que se originó a partir de la idea surgida de las naciones aliadas vencedoras una vez concluida la Segunda Guerra Mundial con el fin de no dejar en la impunidad numerosas crímenes, diversa variedad de abusos y atrocidades perpetradas por el régimen nazi, conductas execrables, muchas de las cuales hasta ese momento no tenían antecedentes en la historia de la humanidad.

Se podría decir pensando dialécticamente que el Tribunal de Núremberg generó conquistas consagradas en Convenios y Tratados Internacionales reconocidos y aprobados por los Estados, alusivos principalmente a la imprescriptibilidad de tales comportamientos punibles y al Principio de Complementariedad en la Administración de Justicia.

En cuanto al Enjuiciamiento de Núremberg, este envió un mensaje a la humanidad que todavía sigue vigente, al extremo que uno de los puntos más controvertidos y polémicos es el tratamiento que se le debe dar a los llamados "Falsos Positivos", ya referenciados en acápites anteriores, con la salvedad que en Alemania se trató de un genocidio, mientras que en Colombia estos fueron calificados por las instancias nacionales e internacionales, como se verá más adelante, como crímenes atroces y de lesa humanidad y por tanto, imprescriptibles y asimismo, sujetos a la justicia complementaria en la eventualidad de fallar la administración de justicia interna y por ende su sujeción o no, a la competencia del Tribunal de Justicia Especial para la Paz (JEP).

En cuanto a España se destaca lo siguiente:

Franco murió en la cama en noviembre de 1975 y tras su muerte nadie habló de crear comisiones de la verdad que investigaran los miles de asesinatos y las violaciones de derechos humanos cometidos durante la dictadura, ni se celebraron juicios contra los supuestos verdugos o responsables de esos actos violentos...

La dictadura de Franco se levantó sobre las cenizas de una guerra civil que había dejado a la sociedad española rota, dividida y con grandes grietas. Duró casi cuarenta años... en España, la Ley de Amnistía del 15 de octubre de 1977, aprobada ya por un Parlamento salido de unas elecciones democráticas, impedía juzgar a los responsables de crímenes y violaciones de derechos humanos cometidos desde las instituciones del Estado franquista. (Cassanova, 2008, p.14).

Por todo ello, se precisa señalar que, durante la dictadura del General Francisco Franco, se distinguen varias etapas. La primera, se caracterizó por el aislamiento y el totalitarismo, sus-

Pensamiento Americano Vol. 11 (22) • 2018 • Julio-Diciembre · Corporación Universitaria Americana · Barranquilla, Colombia • ISSN: $2027-2448$. 
citado después de la terminación de la guerra civil, con el consiguiente sometimiento de los antagonistas del poder. Lo que determinó la hegemonía del bando de los vencedores y el sojuzgamiento de los republicanos y el consiguiente ascenso al poder por parte del General Francisco Franco.

Posteriormente, se produce una segunda etapa caracterizada por una fuerte depresión económica, lo que obligó al replanteamiento de las políticas franquistas. Circunstancia esta que se generó por el aislamiento al que se vio sometida España debido a su apoyo al régimen nacionalsocialista y a su participación en la Segunda Guerra Mundial y, además, por permitir el bombardeo de Gibraltar.

Una tercera fase donde se destaca el desbloqueó a España, la firma de los Tratados de Madrid, en los que dicho Estado, permite a Estados Unidos la instalación en su territorio de bases militares a cambio del otorgamiento de créditos para solventar la difícil situación económica por la que atravesaba en aquel momento. Coyuntura que le permite su reactivación económica, hecho coincidente con el retorno al país de muchas de las personas que habían salido de él en virtud de la fuerte represión militar existente.

En suma, el caso español de los crímenes de lesa humanidad originados en el régimen franquista, quedaron en la impunidad. Sólo se escuchan las voces de los defensores de derechos humanos, para que por lo menos se construya la memoria histórica de lo ocurrido, se conozca la verdad y pueda el pueblo español de una vez por todas lograr la efectividad del Principio de esperanza en la conciencia del tejido social bajo el abrigo de la colocación de un punto final.

Se interrogará: ¿qué parte del mencionado asunto sirve de enseñanza-aprendizaje para lo que ocurre en el territorio colombiano don- de se vive un proceso de Justicia Transicional con ciertos matices similares a los que se han comentado precedentemente?

En este punto se puede asimilar como pauta acorde con la regla de la experiencia que la mencionada impunidad no se repita en Colombia. Pues las circunstancias histórico-materiales actuales son otras, precisamente por la existencia de los Tribunales Internacionales y de la mirada permanente sobre el territorio patrio de los miembros de la Comunidad Internacional que se supone velarán y respaldarán porque no queden sin castigo ni sanción -aun cuando sea de carácter alterativo- los responsables de los delitos atroces de los que han sido víctimas numerosas personas por parte de Agentes del Estado, que pervirtieron de manera sistemática las reglas que rigen los conflictos armados conforme al Derecho Internacional Humanitario, en aras de egoístas conquistas y abyectos propósitos distantes del ejercicio legítimo del poder; por ejemplo la impunidad de las citadas ejecuciones extra judiciales, sarcásticamente denominadas "Falsos Positivos".

Así, en virtud de ello, se han generado respecto al asunto español diversos pronunciamientos que es necesario traer a colación.

...Para el profesor titular de Filosofía del Derecho de la Universidad Carlos III de Madrid, Rafael Escudero, el ejemplo más evidente se dio en la sentencia de 2012 del Tribunal Supremo que rechaza la posibilidad de investigar en sede judicial española los crímenes del franquismo y califica la Ley como "pilar básico e insustituible de la transición española"y, a partir de ahí, se la esgrime como argumento central para rechazar toda investigación (Telesur, 2017, p.2).

A pesar de lo recién citado, se han dado en España algunos conatos que buscaban la re-

Pensamiento Americano Vol. 11 (22) • 2018 • Julio-Diciembre · Corporación Universitaria Americana · Barranquilla, Colombia • ISSN: $2027-2448$. 
vocatoria de la mencionada Ley de Amnistía, tal como ocurrió, verbi gratia en el año 2011, cuando el Partido Popular (PP), el Partido Socialista Obrero Español (PSOE) y Convergencia y Unión (CIU) se opusieron de manera tajante a la iniciativa legislativa que impulsaba la reforma a la famosa Ley, porque con ello se buscaba, cesar con la impunidad.

\section{En Sudáfrica}

Se intentará hacer una aproximación entre las circunstancias de hechoy de derecho que vinculan la problemática que rodea los procesos de justicia transicional y postconflicto de la nación africana y del pueblo colombiano. Así las cosas, se podría inferir si Colombia debe asimilar o por el contrario no tener en cuenta las experiencias suscitadas con ocasión de la mencionada justicia en Sudáfrica.

En lo pertinente, se realizó el siguiente recuento:

...Después de un conflicto armado extremadamente violento, Sudáfrica experimentó una transformación pacífica tras el acuerdo entre los líderes políticos blancos y negros. La aplicación de la justicia transicional y la adaptación de los sudafricanos a la etapa del posconflicto, fueron componentes claves para lograr la paz y la llegada al poder de Nelson Mandela, quien fue presidente de Sudáfrica desde 1994 a 1999. El proceso y la experiencia sudafricana de justicia transicional fue bien reconocida por la comunidad internacional, al punto de concederle a Mandela el Premio Nobel de la Paz en 1993. Y por qué no pensar en que el pueblo colombiano esté dentro de los nominados para este premio, como un reconocimiento a su madurez y compromiso con la búsqueda de la paz. La justicia transicional en Sudáfrica hizo mucho énfasis en el papel que debería desarrollar la Comisión de la verdad y reconciliación...

La confianza en la Comisión permitió revelar muchas verdades y esas verdades ayudaron a la reconciliación y al perdón... (Vélez Gutiérrez, 2015, p.131).

Sin ánimo de ser exhaustivos se podría afirmar que nuevamente se da un componente trascendental en los procesos de justicia transicional como son: la verificación de la verdad de los hechos que generaron el conflicto y su consecuente reparación y concomitante perdón de las víctimas de este, pero con la salvedad que en Sudáfrica se logró conocer lo ocurrido mediante la confrontación de los perpetradores y sus víctimas ante una Comisión de la Verdad y la Reconciliación, integrada por personas pertenecientes al Clero y por personas de prestancia social.

Trayéndose al contexto colombiano la experiencia de la nación africana debe ser internalizada ponderando o asimilando que los procesos de justicia transicional son de carácter excepcional, que no se trata de una justicia retributiva, que los principios de legalidad, necesidad, racionalidad y proporcionalidad de la pena se flexibilizan en aras de la ponderación de los mismos de cara al derecho fundamental a la paz.

En consecuencia, la primera lección que se debe asimilar del pueblo africano, son los conceptos de Verdad, Justicia y Reparación. En segundo lugar, se debe reafirmar que el conflicto sudafricano, al igual que el colombiano fue de larga duración. Sin embargo, el primero de los mencionados comprendía un enfrentamiento entre el poderoso y su servidumbre; vale decir, entre los blancos y los negros. Con la viva intención de sometimiento de los primeros sobre los segundos. Lo que desde luego generaba la resistencia de estos

Pensamiento Americano Vol. 11 (22) • 2018 • Julio-Diciembre • Corporación Universitaria Americana • Barranquilla, Colombia • ISSN: $2027-2448$. 
con la consecuente segregación racial.

Por último, mientras que en Colombia se trató de una lucha armada interna entre los que detentaban el poder político, económico y militar y los desposeídos de la fortuna, donde se pervirtió el ejercicio de la autoridad mediante el abuso desbordado del poder, queriéndose evidenciar una falsa apariencia de dominio y control al presentar los cadáveres de campesinos y civiles inermes, cobardemente asesinados por miembros del ejército, como guerrillero dados de baja en combate. Suscitándose lo que en la historia de Colombia se ha conocido como los "Falsos Positivos" y en el Derecho Penal Internacional tipificada como ejecuciones extrajudiciales, conductas calificadas por dicho ordenamiento como delitos de lesa humanidad.

De otra parte, es importante señalar que, en el marco de los Acuerdos de la Habana, más específicamente en el cuarto punto, se consagró la creación de un Tribunal Especial de Justicia Transicional para la Paz, que representa el eje principal del Sistema de Verdad, Justicia y Reparación y no Repetición. Por ello, en Colombia se creó, mediante el Acto Legislativo 01 de 2017 el Tribunal Especial para la Paz (JEP), conformado por 38 magistrados, que tendrá como principal función juzgar los hechos en que se presentaran violaciones a los derechos humanos y al Derecho Internacional Humanitario cometidos en el marco del conflicto de manera previa a la firma del Acuerdo. E igualmente, garantizar los derechos de las víctimas a la justicia y a conocer la verdad.

Asimismo, es preciso señalar que JEP se compone de tres salas de primera instanciade amnistía, de definición de situación jurídica y de reconocimiento de verdad; contará con un Tribunal de Paz, que hará las veces de segunda instancia; la Unidad de Investi- gación y Acusación, conocida como la Fiscalía de la JEP, y la Secretaría Ejecutiva, que es la encargada del presupuesto.

Además, es de suma importancia precisar para el tema que nos compete, que la Sala de Definición de Situaciones Jurídicas, será la encargada de recibir a los miembros de la Fuerza Pública y funcionarios públicos implicados en hechos relacionados con crímenes graves.

Para finalizar, se quiere enfatizar que el caso colombiano toma algunos matices como los recién mencionados de la experiencia sudafricana, pero aclarándose que son más las diferencias que las semejanzas que los vinculan, pero que en última instancia se aprenderá de ello. Que detrás de todo proceso de Justicia Transicional se producen efectos colaterales como son la desazón, las retaliaciones, la intranquilidad y el inconformismo pero que finalmente terminarán siendo superados.

\section{En América Latina y en Centroamérica.}

De acuerdo con lo planteado seguidamente se abordará lo referente a las vivencias suscitadas en algunos países del cono sur del continente americano y de igual manera se analizarán algunas de América Central. Todas encaminadas a decantar las posibles enseñanzas que se pueden extractar, bien sea, para replicarlas o para desestimarlas.

\section{Argentina}

Cabe destacar en la República Argentina la dictadura militar del General Jorge Rafael Videla en el lapso aproximado de ocho años; época nefasta conocida en la historia de ese país como la de "la guerra sucia" caracterizada por miles de desapariciones forzadas, secuestros, torturas, ejecuciones extrajudicia- 
les, entre otras; mismas distinguidas por la impronta del desbordamiento casi sin límites del poder por diversos motivos, pero con marcado énfasis en los de carácter político.

Al respecto, de manera más detallada se ha expresado:

...La Comisión Nacional sobre la Desaparición de Personas de Argentina (CONADEP) documentó un total de 8.960 muertos y desaparecidos durante el período de 1975 a 1983. Su informe, titulado "Nunca Más" fue el primer reporte publicado por una Comisión de Verdad e indicó, más allá de toda duda, la naturaleza y extensión de la represión por parte del régimen militar. Sin embargo, la política de la verdad en Argentina se vio afectada por las consecuencias que produjo tanto el informe de la CONADEP, como el juzgamiento por parte de los Tribunales argentinos de más de 500 oficiales, - el famoso "juicio a las juntas" - al generar rebelión y resistencia por parte de los militares. Ante las amenazas de desestabilización o de un posible retorno de los militares al poder, primero, el gobierno del presidente Raúl Alfonsín buscó una negociación con los representantes del anterior régimen, y para esto fueron promulgadas las Ilamadas leyes de impunidad (Ley de punto final y Ley de obediencia debida) (Malamud-Goti, 2003). Más tarde, el gobierno de Carlos Menem iría todavía más lejos, indultando por decreto a los militares y participantes de organizaciones armadas que habían sido condenados durante el gobierno de Alfonsín (Niño, 1997). Esto en términos políticos significó que la amnistía se convirtió en la concesión inevitable que tuvo que aceptar la sociedad argentina durante los diez primeros años posteriores a la transición, para evitar el retorno de la dictadura (Cortés Rodas, 2013, p.210).
De lo manifestado, se puede inferir una reinante impunidad para los crímenes atroces y de lesa humanidad perpetrados durante la época de la dictadura de la denominada Junta Militar de Argentina y su aparejado terrorismo de Estado. Situación que se prolongó por varias décadas y que fue interrumpida gracias a la Justicia Complementaria y al ejercicio eficaz y efectivo del Derecho Internacional Humanitario y de los Derechos Humanos.

Respecto a la primera etapa, se destaca que fue relevante por considerar suficiente el mero "esclarecimiento" de los hechos como forma de cumplimiento de los deberes (y las facultades) del Estado argentino en esa dirección.

Luego, la Corte Suprema de Justicia de la Nación sostuvo, en el caso "Arancibia Clavel, Enrique" (Fallos: 327:2312), que por tratarse de delitos de lesa humanidad correspondía la aplicación retroactiva de la imprescriptibilidad de la acción penal.

Y, más tarde, en "Simón, Julio Héctor", declaró la inconstitucionalidad de las leyes 23.492 (punto final) y 23.521 (obediencia debida), negándole a dichas normas cualquier efecto que pudiera oponerse al avance de los procesos o al juzgamiento y eventual condena de los responsables, u obstaculizara las investigaciones en curso (Fallos: 328:2056).

Ello significa que, la sujeción del Estado argentino a la jurisdicción interamericana se dijo en aquel entonces- impedía que el principio de irretroactividad de la ley penal pudiese ser invocado para incumplir los deberes asumidos en materia de persecución de violaciones graves a los derechos humanos, que análogas consideraciones fueron las que Ilevaron al Congreso Nacional, en el año 2003, a dictar la ley 25.779, por medio de la cual el Poder Legislativo declaraba insa- 
nablemente nulas las leyes en cuestión; y si bien se cuestionó la validez de aquella norma, la Corte declaró su constitucionalidad en el mismo precedente "Simón" ya citado.

A partir de esas decisiones se produjo la apertura y avance de una gran cantidad de causas en todo el país y, con ello, una serie de requerimientos por parte de los magistrados encargados de su tramitación.

Para satisfacer las necesidades que se iban presentando, el Máximo Tribunal nacional creó una Unidad de Asistencia y Seguimiento de dichas causas, mediante la acordada 14/07, y de ese modo se fueron canalizando los distintos pedidos efectuados por los tribunales federales" (Centro de Información Judicial, 2017).

En este mismo orden se puede señalar que en Argentina se dio un conflicto interno entre quienes detentaban el poder político, vale decir, la llamada Junta Militar y sus contradictores; asunto que desencadenó en el ejercicio desbordado de la fuerza y del poder de los primeros contra los segundos con resultados de desapariciones, ejecuciones extrajudiciales, asesinatos, torturas, secuestros y pare de contar. Todos calificados como crímenes atroces y de lesa humanidad y cobijados por la amnistía gubernamental que aspiraba sumirlos en la total impunidad.

Adicional a lo anterior no se puede pasar por alto que ese momento histórico se caracterizó por las múltiples protestas de las víctimas y de sus familiares, simbolizadas ante la faz del mundo por las llamadas "Madres de la Plaza de Mayo". Mujeres que por el paso del tiempo terminaron convertidas en "abuelas". Situación que evidencia la total ausencia de respuesta estatal frente a los crímenes que quedaron sin castigo y que sólo a partir de las reclamaciones, ante los Tribunales In- ternacionales referenciados, comenzaron a aflorar algunas verdades de lo ocurrido.

Muestra de ello lo constituyen los procesos penales que cursaron o cursan ante las autoridades jurisdiccionales argentinas ante la declaratoria de imprescriptibilidad de la acción penal por tratarse de crímenes atroces y de lesa humanidad y, por tanto, el desconocimiento de los Principios de la Cosa Juzgada y de la Seguridad Jurídica.

\section{Chile}

En cuanto a la experiencia chilena se debe destacar, que al igual que lo sucedido en Argentina, se vivió una dictadura militar, encabezada por el General Augusto Pinochet, durante el periodo comprendido entre 1973 y 1997. Época en la cual el mencionado régimen convivió con la extralimitación, abuso o desviación del poder, de manera que todos aquellos que se opusieron al régimen, terminaron siendo perseguidos, desaparecidos, torturados, sometidos a toda clase de vejámenes y desde luego, a las no menos importantes, ejecuciones extrajudiciales. Conductas atribuidas a quienes detentaban el poder o a sus agentes.

Durante el régimen militar chileno y frente a la proliferación de crímenes atroces y de lesa humanidad y a la posibilidad de autoría de los Agentes del Estado urgió la necesidad de una autoamnistía, que se plasmó en el Decreto Ley 2191 de 1978, suscrito por el propio Augusto Pinochet Ugarte y sus colaboradores.

Dicho Decreto Ley representa el sumun de la vulneración de los derechos y garantías propios de un Estado de Derecho. Desconoció flagrantemente el Principio de Legalidad y su cointegrador Principio de Reserva, pues en este caso fue el propio Dictador quien abanderó la impunidad ante la posibilidad 
de autoría y del riesgo de aplicación de la ley penal. Posteriormente, ya alejado de los círculos del poder, el General Augusto Pinochet Ugarte es detenido en la ciudad de Londres en el año 1998 en virtud de una solicitud que en tal sentido formulara el Juez español Baltasar Garzón.

Al cabo de 16 meses de estudio y deliberaciones, finalmente la Cámara de los Lores de Inglaterra determinó que Pinochet no estaba amparado por ninguna inmunidad y que en consecuencia podría ser juzgado. Sin embargo, debido a su precaria condición de salud, el Primer Ministro inglés de la época, Tony Blair, decide poner en libertad al exdictador, quien finalmente regresa a Chile en el año 2000.

Nuevamente surge el lugar común de dejar sin sanción penal los crímenes atroces y de lesa humanidad perpetrados en el marco de conflictos internos acaecidos en el contexto de países latinoamericanos. Se repiten las situaciones y se reiteran los intentos de impunidad después de largos periodos de abusos del poder. Quedando un mensaje negativo en el ámbito de la administración de justica transicional. La que a la postre nunca llegó, sino que finalmente de una manera o de otra terminó en las instancias jurisdiccionales de derechos de humanos, en el caso particular del General Pinochet con la feliz coincidencia de entrar en vigor el Estatuto de Roma y la Corte Penal Internacional, encargada de juzgar a las personas acusadas de cometer crímenes de lesa humanidad, guerra y genocidio.

En síntesis, en Argentina y Chile se dieron curiosas coincidencias, "...en ambos países, más de dos décadas después, los tribunales nacionales, bajo la presión internacional, enjuiciaron y condenaron a algunos miembros de los regímenes militares autores de crímenes atroces. No obstante, víctimas, activistas y defensores de derechos humanos afirman que la justicia en ambos países fue poca y llegó demasiado tarde.

Para Colombia, la lección que deja la experiencia en Chile y Argentina es que la Justicia Transicional tiene que ser rápida y eficaz para crear confianza, seguridad y tranquilidad en la sociedad; y mandar un mensaje claro en cuanto a que se puede hacer justicia y negociar la paz sin impunidad, valiéndose de ella" (Vélez Gutiérrez, 2015, p.128).

\section{Perú}

En el caso del Perú, es importante destacar que vivieron un periodo de confrontación armada que se desarrolló entre 1980 y 1990, que culminó con la captura y el encarcelamiento de Abimael Guzmán máximo Líder del Grupo Sendero Luminoso, principal grupo subversivo que operó en el mencionado país suramericano. No hubo un proceso de paz, se dio el juzgamiento de los vencidos por parte de los vencedores.

Cabe resaltar que luego de la captura y de la judicialización de las referidas personas, no hubo un proceso de Justicia Transicional. El Estado se limitó a perseguir y a encarcelar a los miembros del Partido Comunista y a todos los principales líderes y activistas de las organizaciones de derechos humanos, so pretexto de que estos hacían parte o que apoyaban las ideas de los grupos terroristas.

En la actualidad, pese a haber alcanzado una avanzada edad muchos de los reos, aún continúan privados de la libertad, sin que hasta el momento se haya dado de manera efectiva un proceso de reconciliación democrática y de esclarecimiento completo de la verdad. Hasta el punto de que activistas de derechos humanos claman porque el Estado peruano emule al Estado colombiano y realice todo lo necesario para que aquel viva y asuma su

Pensamiento Americano Vol. 11 (22) • 2018 • Julio-Diciembre · Corporación Universitaria Americana · Barranquilla, Colombia • ISSN: $2027-2448$. 
propio proceso de justicia transicional.

De acuerdo con lo expresado, se sugiere que el Perú aproveche la experiencia de Colombia para que de una vez por todas resuelvan y superen sus diferencias, alcancen el perdón y la reconciliación nacional.

En este orden de ideas, en lo relacionado con el conflicto bélico interno del Perú, se debe apreciar que, en lugar de servir como referente para Colombia en cuanto a la implementación de un modelo de Justicia Transicional, se debe anotar que de acuerdo con el estado de cosas, Colombia ha avanzado más en ese sentido a pesar de que su conflicto armado interno fue más prolongado. De manera que la lección aprendida es que se debe seguir adelante sin perder de vista que los aportes de la Comisión de la Verdad en Colombia deberían servir no solamente como un mero documento de la memoria histórica, sino que debe ser un instrumento para la eficaz visibilización y reparación de las víctimas y judicialización alternativa de los perpetradores.

\section{El Salvador}

De igual forma que en los países americanos relacionados anteriormente en El Salvador también se suscitó un conflicto interno pero bajo la modalidad de una guerra civil. Al respecto se debe aclarar que dicha situación, jamás fue calificada o reconocida oficialmente por el Gobierno de la época.

En todo caso, el conflicto interno salvadoreño, cualquiera que sea la denominación que se le pretenda dar, se prolongó por más de una década; vale decir, en el período comprendido entre los años 1980 y 1992; lapso durante el cual, según el informe final de la Comisión de la Verdad auspiciada por la ONU, se produjeron más de 70.000 muertes violentas relacionadas directamente con dicha confrontación armada.

Los protagonistas de la actividad bélica fueron las Fuerzas Regulares del Estado y el Frente Farabundo Martí para la Liberación Nacional (FMLN). Ante el estado de cosas y los atentados permanentes contra los Derechos Humanos y el Derecho Internacional Humanitario el pueblo salvadoreño firmó un acuerdo de paz con el respaldo de las Naciones Unidas, la iglesia católica y con el acompañamiento de otros Estados.

Después de años de deliberaciones, la Sala de lo Constitucional de la Corte Suprema de Justicia de El Salvador resolvió el 13 de julio de 2016 que la Ley de Amnistía de 1993 era inconstitucional y por tanto inválida...

La sentencia se origina en una acción de inconstitucionalidad que varios representantes de organizaciones de sociedad civil y víctimas de violaciones de derechos humanos promovieron en año 2013, en la cual sostenían que la Ley de Amnistía había sido aprobada de manera ilegal y resultaba violatoria de los compromisos internacionales asumidos por EI Salvador y de lo estipulado en la Constitución del país. La amnistía de 1993 se había dictado para responder a los delitos perpetrados por ambas partes de la guerra civil, en la cual se perdieron alrededor de 75.000 vidas. La amnistía se aprobó tan solo tres días después de que la Comisión de la Verdad patrocinada por la Organización de las Naciones Unidas (ONU) emitiera su informe. La Comisión llegó a la conclusión de que la mayoría de los asesinatos, masacres, desapariciones forzadas y torturas que ocurrieron en ese período habían sido cometidos por miembros de las fuerzas armadas o por escuadrones de la muerte vinculados a ellas... (Roht Arriaza, 2016, p.3). 
Las vivencias salvadoreñas al parecer fueron tenidas en cuenta por Colombia, porque entre ambos procesos hay varios puntos de convergencia, por ejemplo, el tema agrario hizo parte fundamental dentro de las negociaciones de La Habana, hasta el punto de ser incluida la cuestión de una reforma agraria integral como uno de los principales puntos en la Agenda de las negociaciones del Gobierno con la guerrilla. Del mismo modo hizo parte de los Acuerdos o negociaciones de paz el compromiso por parte del Estado de la expedición de la Ley de Restitución de Tierras.

\section{En Colombia.}

En consideración a la forma como se seleccionaron los países con precedentes en el asunto materia de este acápite, parecerá extraño que se incluyera a Colombia, cuando lo que se persigue es destacar las lecciones o experiencias arrojadas en sus conflictos internos frente a la violación de los Derechos Humanos y del Derecho Internacional Humanitario.

Realmente no resulta sorprendente si se tiene en cuenta que Colombia ostenta el primer lugar entre los países del mundo que más procesos de paz ha implementado sin los resultados que se esperaban.

Por tanto, es de recibo traer a colación las siguientes reflexiones que dimensionan la magnitud del problema que actualmente vive Colombia y, asimismo, el sinnúmero de expectativas que este nuevo intento ha suscitado, si se tiene en cuenta la profunda polarización ideológica existente entre diversos sectores de la política nacional.

Colombia es el único país del mundo que ha hecho diez procesos de paz en los últimos treinta años. En ese período, cada gobierno combinó descentralización, desmovilizaciones pactadas y programas presidenciales especiales e hizo su propia receta para lidiar con la presión social y regional por inclusión, para someter e incorporar a los grupos armados ilegales y para fortalecer el Estado...

Aproximadamente cada cincuenta años una generación de colombianos ha tenido la oportunidad de decir cómo acabar con una guerra de larga duración y cómo construir instituciones para un país moderno, incluyente y en paz. Primero le tocó a la generación que vivió el fin de la Guerra de los Mil Días a inicios del siglo XX. Luego a la generación que padeció la violencia bipartidista y se inventó el Frente Nacional. Y ahora es nuestro turno.

Si aprendemos de nuestra propia experiencia, esta generación pasará a la historia como la que puso fin al último conflicto armado de todo el hemisferio occidental y logró que dejáramos de ser tres países que se desconocen y recelan y seamos por fin una sola Colombia... (López, 2016, pág. 1).

Se podría arribar a una peregrina deducción: los procesos de paz que antecedieron a los Acuerdos finales de La Habana, Cuba sirvieron de experiencia para no cometer los mismos errores del pasado, lástima que las circunstancias que vive el país de inconformismos, de falencias, de miedos, de manipulación, entre otros, podrían afectar las buenas intenciones que lo gestaron pues abundan serios intereses que quieren volver "trizas ese maldito papel" que duró más de seis años para poder construirse y que la comunidad internacional reconoció hasta el punto que por primera vez en la historia un Presidente de Colombia logra obtener un Premio Nobel de la Paz.

Se han planteado argumentos a favor de la 
paz que por considerarse pertinentes es del caso traer a colación.

A esto se contrapone otra evidencia histórica: sociedades en que imperó por largo tiempo el crimen sistemático e incluso oficializado (esclavitud, servidumbre, cruzadas, inquisición, conquistas, colonizaciones, piratería oficial, dictaduras, guerras de agresión, expoliación de pueblos y recursos naturales, opresión general y hasta genocidios enormes) han podido alcanzar la paz sin demasiado derecho penal y han sobrevivido en paz prolongada a pesar de la impunidad generalizada y casi total (Alemania nazi, Sudáfrica, México, El Salvador, Bélgica, etc., etc., y desde luego, al menos en el intento, Colombia). Parece que cuando una sociedad pierde su paz recuperarla tiene también su precio, y de esto trata la cada vez más famosa "justicia transicional"- que hoy parece vivir en conflicto con la "justicia de víctimas" (prelación de la reparación integral sobre los derechos de los imputados, imprescriptibilidad de las graves lesiones a los derechos humanos) ... (Fernández Carrasquilla, 2011, pág. 48).

Por último vale la pena mencionar los informes que se han surtido con ocasión de los conflictos bélicos que han vivido algunos países europeos con motivo de la Segunda Guerra Mundial y su posterior fase de justicia transicional. En tales términos, el académico e investigador Luc Huyse elaboró un informe sobre la base de los resultados obtenidos con ocasión de la posible implementación de una justicia transicional. En punto de lo anterior se expresa lo siguiente:

"El proyecto Justicia transicional después de la guerra y la dictadura: aprendizajes desde la experiencia europea (1945-2000) lo inició Luc Huyse, que desde hace años trabaja en el campo de la justicia transicio- nal como académico y asesor. El proyecto se puso en marcha gracias a la colaboración entre la División para el Desarrollo de la Paz del Servicio Público Federal Belga de Asuntos Exteriores, que lo financió, y el Centro para la Investigación y la Documentación Históricas sobre la Guerra y la Sociedad Contemporánea de Bélgica (CEGES/SOMA), que asumió las labores de coordinación. Esta colaboración refleja el doble carácter del proyecto, que se orienta tanto a la elaboración de políticas como a la investigación académica.

La primera fase del proyecto, principalmente académica, se desarrolló entre abril de 2011 y enero de 2012. Se seleccionaron nueve países europeos, con diez casos de estudio, para constituir el "grupo de referencia» histórico. Bélgica, Francia, Holanda y Alemania (Occidental) cubren el contexto posterior a la Segunda Guerra Mundial. Portugal, España y Grecia representan la llamada segunda ola de transiciones democráticas. Alemania, Polonia y Hungría cubren las transiciones posteriores a 1989.

Este proyecto cuenta con una importante ventaja: el prolongado periodo transcurrido desde que se concibieron y ejecutaron las políticas analizadas. Esto permitió al equipo (al investigador principal, a los demás autores y al director del proyecto) observar repercusiones a largo plazo de dichas políticas como son las consecuencias intergeneracionales, los duraderos efectos de las opciones relativas a desafíos recurrentes y la secuencia de las acciones. Esta amplia perspectiva temporal es precisamente lo que falta en la mayoría de los experimentos que se centran en «lecciones aprendidas»." (Huyse, 2013).

En consecuencia, en el caso de las Ejecuciones Extrajudiciales o "Falsos Positivos", deben responder penalmente no solo los soldados

Pensamiento Americano Vol. 11 (22) • 2018 • Julio-Diciembre • Corporación Universitaria Americana • Barranquilla, Colombia • ISSN: $2027-2448$. 
o policías de bajo rango, sino, además, en virtud de la doctrina de la cadena de mando, los superiores jerárquicos, o sea el Comandante que dio la orden, o quien o quienes no impidieron que se consumaran los hechos e igualmente los funcionarios encargados de investigar los mismos y que no lo hicieron.

En tal sentido, se podría afirmar que están dadas las condiciones para que en Colombia no queden en la impunidad las ejecuciones extrajudiciales o "Falsos Positivos". La Comunidad Internacional sigue con atención el acontecer del postconflicto y la efectividad sancionatoria para los perpetradores de estos crímenes atroces y que no se repita lo que se suele decir, analógicamente: el derecho penal es como las telarañas atrapa a los animales pequeños, pero es desgarrado por los animales grandes. No es capaz de confrontar a los poderosos.

\section{Referencias}

Carrió, G. R. (1990). Notas sobre Derecho y Lenguaje. Buenos Aires: Abeledo Perrot.

Cassanova, J. (14 de Septiembre de 2008). La Recuperación de la Memoria. Diario El País, págs. 12-24.

Corte Suprema de Justicia de la Nación. (2004 de Agosto de 24). Caso Arancibia Clavel, Enrique, 259.

Centro de Información Judicial. (2017). Descripción general de los juicios en la Argentina Agencia de Noticias del Poder Judicial. Buenos Aires, Argentina: Agencia de Noticias del Poder Judicial. .

Constitución Política de Colombia. (1991). 2da Edición Legis.

Cortés Rodas, F. (2013). El derecho internacional penal y el asunto de la amnistía. El caso de las Farc. Revista Iberoamericana de Filosofía, Política y Humanidades, 200-220.

Corte Suprema de Justicia de la Nación. (24 de Agosto de 2004). Fallos: 327:2312, 259

Corte Suprema de Justicia de la Nación. (14 de Junio de 2005).Fallos: 328:2056, 17.768

Larousse Gran Diccionario. (2016). Gran Diccionario de la Lengua Española. Obtenido de The Free Dictionary: https://es.thefreedictionary.com/ontolog\%c3\%ada

Las cuatro críticas de la fiscal de la CPI a la Justicia Especial para la Paz. (21 de Octubre de 2017). Revista Semana. Recuperado de Revista Semana web site: https://www.semana.com/nacion/articulo/los-reparos-de-la-fiscal-de-la-cpi-a-la-justicia-especial-depaz/544474

López, C. (2016). ¡Adiós a las Farc! ¿Y ahora qué? Construir ciudadanía, Estado y mercado para unir las tres colombias. Bogotá, Colombia: Pengüin Random House Grupo Editorial Colombia. 
Malamud-Goti, J. (2003). Los dilemas morales de la Justicia Internacional. Buenos Aires, Argentina: Miño y Dávila Editores.

Montoro Ballesteros, A. (2000). En torno a la idea del delito político. Anales de Derecho, 131-156.

Niño, C. S. (1997). Juicio al mal abuso. Buenos Aires, Argentina: Emecé.

Ortíz Rivas, H. A. (2004). Kant y la Paz Perpetua, Homenaje en el bicentenario de la muerte de Kant. Bogotá, Colombia: Colección de Estudios Breves.

Pérez Pinzón, Á. O. (1986). Curso de Criminología. Bogotá, Colombia: Temis.

Roht Arriaza, N. (2016). Tras la invalidación de la Ley de Amnistía por la Corte Suprema de Justicia de El Salvaor: ¿vienen investigaciones penales? Blog de la Fundación para el Debido Proceso, 1-7.

Salas, G. (2012). Delitos contra la Humanidad. Ciudad de México: Porrúa.

Servín Rodríguez, C. A. (2014). La evolución del crimen de lesa humanidad en el derecho penal internacional. Boletín Mexicano de Derecho Comparado, 209249.

Telesur. (17 de Octubre de 2017). Cuarenta años de impunidad a los crímenes del franquismo. Telesur, págs. 1-5.

Vélez Gutiérrez, L. F. (2015). Justicia Transicional en Colombia: hacer justicia o negociar la paz. Estudios comparativos. Bogotá: Universidad Sergio Arboleda. 